\title{
David Hume e o "número de Dunbar": uma abordagem evolucionista sobre os fundamentos da moralidade
}

\author{
David Hume and "Dunbar's number": \\ an evolutionary approach to the foundations of morality
}

* Marcelo de Araujo

Resumo: O objetivo deste artigo é caracterizar o conceito de justiça como uma convenção social indispensável para a emergência de obrigações morais no contexto de grupos que ultrapassam o "numero de Dunbar". O artigo retoma, por um lado, a teoria da justiça proposta por David Hume na terceira seção de Uma Investigação sobre os Princípios da Moral, e, por outro lado, a hipótese de Robin Dunbar acerca do número máximo de indivíduos com os quais uma pessoa pode manter relações sociais estáveis que envolvam laços de amizade, vínculos de família, e histórias pessoais compartilhadas.

Palavras-chave: David Hume. Número de Dunbar. Justiça. Evolução. Sentimentos Morais.

Abstract: The aim of this article is to characterize the concept of justice as an indispensable social convention for the emergence of moral duties in the context of groups that surpass the so-called "Dunbar's number". The article resumes, on the one hand, David Hume's theory of justice, as it is discussed in the third section of An Enquiry Concerning the Principles of Morals, and on the other hand it resumes Robin Dunbar's hypothesis relative to the maximum number of individuals with whom a person may keep stable social relationships that comprise kinship, fellowship, and a sense of shared personal histories.

Keywords: David Hume. Dunbar's Number. Justice. Evolution. Moral Sentiments.

* Doutor. Professor de Filosofia da Universidade Federal do Rio de Janeiro e da Universidade do Estado do Rio de Janeiro. Esta pesquisa contou com apoio financeiro do CNPq e da Fundação Alexander von Humboldt. <marcelo.araujo@pq.cnpq.br> 
Ta Seção III de Uma Investigação sobre os Princípios da Moral 1 (1751) Hume trata do conceito de justiça. A justiça, para Hume, é uma convenção social. Ela diz respeito à instituição da promessa e da propriedade privada. A convenção da justiça nos permite lidar com duas circunstâncias básicas da vida humana: [1] Os recursos indispensáveis para a preservação da vida humana são, de modo geral, relativamente escassos. [2] As pessoas com as quais interagimos, de modo geral, podem não ser completamente egoístas e ardilosas, mas elas também não costumam ser inteiramente abnegadas e altruístas. E mesmo quando são abnegadas e altruístas, a abnegação e altruísmo de que muitas pessoas são capazes raramente são mobilizados em prol da humanidade como um tudo, mas geralmente em benefício de um círculo relativamente limitado de pessoas. Por essa razão, em contextos em que os recursos naturais são relativamente escassos, e é limitada nossa propensão para agirmos com generosidade, ou abnegação, devemos pensar num "esquema" capaz de impor algum limite à propensão bastante comum que as pessoas têm de privilegiar a implementação do próprio interesse em detrimento do interesse das pessoas que lhes são estranhas. Em alguns textos Hume, ele próprio, usa a palavra "esquema" (scheme) para se referir aos limites impostos pelas regras de justiça ${ }^{1}$.

Hume não tenta dar uma resposta sistemática à pergunta sobre como os princípios da justiça efetivamente surgiram. Embora Hume conceba a justiça como uma "convenção" humana, ele rejeita a suposição de que essa convenção possa ter resultado de um "contrato social". A convenção da justiça deve ter surgido espontaneamente entre as pessoas a partir de uma percepção mútua de "interesses comuns"2. Mas a emergência da convenção da justiça, por outro lado, está subordinada a certas circunstâncias específicas da vida humana. A tese de Hume é que a convenção da justiça não poderia surgir nem em circunstâncias de abundância nem em circunstâncias de escassez. No cenário de abundância a convenção da justiça seria desnecessária. No cenário de escassez ela seria inútil. A justiça, segundo Hume, somente faz sentido nessa "região intermediária" (medium), situada entre esses dois tipos opostos de circunstâncias extremas: o cenário de abundância e o cenário de escassez. Vejamos melhor esses dois pontos separadamente.

1 Cf. Hume An Enquiry Concerning the Principles of Morals, Appendix III (1968, p. 276; 277; 278; 279); Hume A Treatise of Human Nature (1978, p. 497; 522; 539; 579; 580).

2 Hume A Treatise of Human Nature (1978, p. 490). 


\section{O Cenário de abundância}

Se as pessoas fossem fortemente benevolentes ou generosas e, além disso, os recursos de que necessitam fossem abundantes, seria desnecessário "vincular" (bind) uma pessoa à realização de uma ação através de uma promessa, ou através da exigência de respeito à propriedade privada. Isso seria desnecessário, em primeiro lugar, porque as pessoas já teriam em abundância tudo de que necessitam e, em segundo lugar, porque elas já se sentiriam fortemente motivadas a agir para o benefício de outros indivíduos. Por que, por exemplo, uma mãe prometeria ao filho que ela dará para ele o almoço todos os dias, ou por que ela se absterá de se apossar de algum objeto do filho, se ela já se sente suficientemente motivada a fazer isso por força dos laços afetivos que têm com o filho? A mãe que alimenta seu filho apenas porque prometeu fazer isso, ou se abstém de roubar algum objeto do filho apenas por uma questão de respeito à propriedade privada, estará certamente sendo justa, mas haverá a dúvida sobre se ela é também uma boa mãe. Ocorre, porém, que a expectativa de que uma mãe realize ações para benefício do filho por força de certos laços afetivos é, segundo Hume, tão constitutiva da moralidade quanto a ideia de justiça ${ }^{3}$.

A justiça é necessária para que realizemos ações para benefício mútuo em contextos nos quais os recursos de que precisamos não são abundantes, e os laços afetivos entre as pessoas são fracos, ou simplesmente inexistentes. Ao nos "vincularmos" à realização de uma ação através de uma promessa, ou através do respeito à propriedade privada, nós, por assim dizer, nos vemos "amarrados" ou "atados", como que impedidos de realizar uma ação diferente daquela especificada pela promessa ou pelo respeito à propriedade privada. Esse "vínculo" gerado pela promessa, ou pela exigência de respeito à propriedade privada, nos impede de privilegiar nosso próprio interesse em detrimento do interesse de outras pessoas. Esse vínculo nos impede também de privilegiar o interesse das pessoas que nos são próximas em detrimento das pessoas que nos são completamente estranhas. Em inglês, a metáfora sugerida pelo verbo correspondente ao verbo "vincular" é ainda mais nítida do que ocorre em português, pois o verbo usado nesses contextos, inclusive por Hume, é to bind: "amarrar", "atar", "vincular". Em português o verbo "vincular" também pode ter um sentido normativo, mas "vincular" é menos usado em português com esse sentido normativo do que o

3 Hume On the original contract (1994, p. 195-196). 
verbo to bind em inglês ${ }^{4}$. Vejamos agora o cenário oposto ao cenário de abundância: a escassez.

\section{O cenário de escassez}

No cenário de escassez, segundo Hume, a justiça seria inútil. Imaginemos dois náufragos que têm como único instrumento de salvação uma prancha de surf. Imaginemos que a prancha seja muito pequena e que pode continuar flutuando com apenas um dos náufragos, mas não com os dois. Se um indivíduo for o proprietário da prancha, e puder inclusive provar isso no meio do oceano, ele poderia realmente esperar que o outro indivíduo abrisse mão da prancha apenas por uma questão de respeito à propriedade privada? $\mathrm{E}$ se um tiver prometido a prancha para o outro: aquele que prometeu estará agora "vinculado" à cessão da prancha para o benefício do outro? Quando os recursos são extramente escassos, como uma prancha de surf nesse caso, é inútil falarmos em promessas ou em propriedade privada, pois os indivíduos tenderão a privilegiar o próprio interesse sem fazer concessões para o benefício de outros indivíduos. Parece-me que num caso como esse, se um indivíduo tomar a prancha do outro, ou se recusar a devolvê-la ao proprietário, ele não será percebido mais tarde por outras pessoas, caso o incidente se torne público, como uma pessoa injusta, como uma pessoa incapaz de respeitar a propriedade privada ou de cumprir uma promessa. Esse indivíduo, a meu ver, pode não ter agido como uma pessoa abnegada e altruísta, mas nem por isso poderíamos dizer que ele cometeu uma injustiça.

Mas se a pessoa que se afogou era seu amigo ou seu filho, o indivíduo poderá mais tarde ser severamente criticado por não ter agido em consonância com vínculos afetivos e laços de lealdade que unem amigos ou familiares. E isso, em algumas circunstâncias, pode até ser percebido como moralmente mais grave do que o descumprimento de uma promessa ou a violação da propriedade privada. Por outro lado, se um indivíduo voluntariamente se sacrificar nessas circunstâncias em prol de uma criança, ou mesmo em prol de um estranho, ele poderá ser lembrado mais tarde como um herói, como uma pessoa de valor moral inestimável, e não simplesmente como uma pessoa que apenas fez o que se exigia dela por uma questão de justiça. Gestos de heroísmo ou de abnegação envolvem altas doses de motivações como benevolência, altruísmo, amor, ou lealdade. Mas de ninguém se exige agir como um herói apenas por uma questão de justiça.

4 Cf. Dicionário Houaiss: "vincular: [...] ligar(-se) afetiva ou moralmente (algo ou alguém) [a]". 
No cenário de escassez extrema, se os indivíduos forem predominantemente egoístas e ardilosos, a perspectiva de que haja alguma cooperação entre eles é, evidentemente, bastante precária. Por outro lado, indivíduos egoístas e ardilosos poderiam cooperar entre si num cenário em que a escassez fosse apenas moderada. Se é verdade que "o homem é o lobo do homem", então, para superar uma "guerra de todos contra todos", os indivíduos poderiam concordar em criar a justiça com o objetivo de prevenir a violência mútua e de, com isso, auferir os benefícios da cooperação social. A superação de uma guerra de todos contra todos seria motivada, não pela compreensão coletiva do que é bom para todos, mas pela percepção individual do que é mais vantajoso para si. Vários autores na tradição do contrato social, Hobbes particularmente, conceberam a instituição da justiça como um artifício para lidar com o caráter autointeressado da natureza humana em contextos de escassez. Hume se refere explicitamente a Hobbes ao analisar o cenário de escassez descrito na Seção III da Investigação sobre os Princípios da Moral. As circunstâncias da abundância, por outro lado, parecem ter sido menos discutidas na tradição de investigação filosófica acerca do conceito de justiça. Mas, a meu ver, o cenário de abundância talvez seja mais relevante para nossa compreensão da moralidade do que o cenário de escassez. Gostaria de explicar melhor esse ponto.

\section{Grupos pequenos e grupos grandes}

O que caracteriza a situação de abundância, segundo Hume, não é apenas a abundância de recursos, mas também a abundância de disposições pró-sociais. Se os recursos de que necessitamos existissem em abundância e, além disso, as pessoas com as quais interagimos fossem predominantemente generosas (ou benevolentes, abnegadas, altruístas, etc.) não faria sentido falarmos em justiça. Por que, por exemplo, entrarmos em um debate sobre como dividirmos o ar que respirarmos, se: [1] o ar é suficiente para todos, e [2] todos já se sentem fortemente motivados a agir uns em prol do bem estar dos outros? A relação entre as pessoas no cenário de abundância não é regulada pelas regras de justiça, mas nem por isso a relação entre as pessoas deixa de ser moral: cada um visa o bem do outro, talvez até mesmo mais do que vise seu próprio bem. Contudo, um não está "vinculado" ao bem estar do outro pelas exigências da justiça, mas por força de laços afetivos e disposições morais como benevolência, gratidão, generosidade, compaixão, amizade, etc.

Dizer que no cenário de abundância não haveria ainda as regras de justiça não significa dizer que não haveria aqui nenhum tipo de regra 
ou convenção. Um indivíduo pode estar fortemente motivado a agir em prol de outros indivíduos, mesmo que isso envolva um alto grau de auto-sacrifício. Mas ele não poderá agir em prol de todos os indivíduos ao mesmo tempo. Por essa razão, no cenário de abundância os indivíduos podem concordar que seria importante criar regras para coordenação de suas respectivas ações. Por exemplo: alguns caçam enquanto outros cuidam das crianças. A existência de regras relativas à alocação de tarefas é uma garantia de que a alta motivação de A para agir em prol do bem-estar de B (e em prol do bem estar das outras pessoas com as quais A e B cotidianamente interagem) não será mobilizada para gerar resultados aquém dos resultados que todos poderiam obter se não houvesse uma regra para coordenação de suas ações. Sem essa regra é possível que, em um dado momento, A e B, por exemplo, se encontrem para caçar sem que haja alguém para cuidar das crianças. Mas essa ainda não é uma regra de justiça. Trata-se de uma regra de coordenação. Apenas por esquecimento, mas não por oportunismo, A ou B descumpririam a regra, pois estamos assumindo aqui que tanto A quanto B estejam fortemente motivados a dar o melhor de si, um em prol do bem-estar do outro. B pode ficar desapontado com o esquecimento de A, caso A não cumpra a regra de coordenação, mas $B$ ainda não poderia chamar $B$ de injusto.

É desnecessário nos perguntarmos se houve em algum momento na história da humanidade um cenário de abundância como esse, ou seja: um cenário em que não faltariam os recursos naturais indispensáveis para a vida das pessoas e no qual os seres humanos se sentiriam fortemente motivados a agir um em prol do bem estar do outro. $O$ que interessa a Hume é delimitar as circunstâncias da justiça, sem se comprometer com a suposição de que possa ter havido no passado um cenário de abundância, e sem se comprometer também com a pergunta sobre se seria possível instaurarmos no futuro um cenário como esse. O cenário de abundância descrito por Hume é meramente hipotético, pois de modo geral as circunstâncias do mundo em que vivemos são tais que os recursos de que dependemos não são abundantes, e além disso as pessoas com as quais cotidianamente interagimos não são de tal modo benevolentes a ponto de ser desnecessário o apelo a promessas e à exigência de respeito à propriedade privada para regrarmos nossa interação com elas. Hume, na verdade, não retorna à discussão dessa hipótese na sequencia da Investigação.

Embora sejamos capazes de agir por força de disposições como benevolência, gratidão, generosidade, etc. a ponto de, em algumas situações, nos sacrificarmos em prol de pessoas que nos são afetivamente próximas, de modo geral não temos essas disposições relativamente 
a todas as pessoas. Frequentemente temos de interagir com pessoas com relação às quais não temos nenhum vínculo de amizade, lealdade, compaixão, laços de família, ou inclinações afetivas especiais. Por outro lado, em grupos relativamente pequenos, é razoável supor que as circunstâncias do cenário de abundância podem ser menos hipotéticas do que o argumento de Hume sugere. Eu gostaria de explicar melhor esse ponto.

Os membros de uma pequena sociedade de pescadores, numa região em que não faltem nem peixes, nem água potável, nem os recursos naturais para o preparo e consumo dos peixes, poderiam facilmente viver como os indivíduos que se encontram nas circunstâncias de abundância descrita por Hume. Nessas circunstâncias, segundo Hume, não existiria ainda a instituição da "propriedade privada" e da "promessa". Mas dizer que no cenário de abundância não precisaríamos da justiça não é a mesma coisa que dizer que a justiça não poderia existir nessas circunstâncias. Nas circunstância de abundância, vigentes em um grupo pequeno, a instituição da justiça poderia até surgir, mas ela não seria imprescindível. O importante é que os membros desse grupo já poderiam se amparar em um amplo vocabulário normativo na hora de resolver eventuais conflitos de interesse. Se surgir algum conflito entre A e B, A pode dizer para B que $B$ foi ingrato por não tê-lo ajudado, pois $A$ ajudou $B$ em outras ocasiões, ou ajudou os irmãos ou pais de B no passado. A pode dizer que B não se comportou como um amigo; ou que B agiu sem compaixão, ou que B não foi leal a $A$, ou que $B$ não foi leal ao grupo como um todo. Isso de que A lança mão ao se dirigir a $B$ - a referência aos laços de amizade, lealdade, e a certos sentimentos como gratidão e compaixão - deve ser compreendido por B como um argumento na discussão sobre como resolverem seus conflitos. A poderia também lançar mão do vocabulário da justiça e dizer que $B$ deixou de cumprir uma promessa, ou violou a propriedade privada de $\mathrm{A}$, ou de uma terceira pessoa. Mas a referência ao vocabulário da justiça seria apenas mais uma ideia normativa de que A poderia lançar mão relativamente à conduta de $B$. Os argumentos de que A lança mão podem ser basicamente os mesmos argumentos de que também lançaríamos mão ao interagirmos com pessoas que nos são muito próximas tais como amigos e familiares. Vínculos de amizade e laços de família possuem - à falta de termo melhor - uma "dimensão normativa", ainda que nem sempre possamos determinar com precisão o conteúdo das obrigações e compromissos decorrentes desses vínculos e laços. Em um grupo relativamente pequeno, as relações são predominantemente regradas por laços ou vínculos como esses, e em função também de uma história compartilhada. A biografia de cada um se entrecruza com a biografia de todos os demais. Esses vínculos, 
laços e disposições predominantes entre indivíduos que compartilham histórias comuns geram a expectativa de lealdade, que é, sem dúvida, uma disposição moral importante. O problema, porém, é que eu posso ser justo para com todas as pessoas do mundo, mas não faria sentido dizer que sou leal a todas elas. Eu posso ter laços afetivos e vínculos de lealdade que geram para algumas pessoas a expectativa de que eu me conduza relativamente a elas de uma determinada maneira. Mas eu não posso ter laços e vínculos desse tipo com todas as pessoas do mundo. Lealdade, diferentemente da justiça, exige seleção e exclusividade. A justiça, por outro lado, exige imparcialidade. A justiça exige de nós um determinado tipo conduta que independe dos laços e vínculos afetivos que possamos ter com as pessoas.

Parece-me que é irrelevante para a reconstrução do argumento defendido por Hume a pergunta sobre se um grupo pequeno, que vive em consonância com as circunstâncias de abundância, poderia prescindir das regras da justiça. É razoável supor que um grupo como esse poderia ver surgir aos poucos regras sobre a propriedade privada e sobre promessas. Mas essas regras, a meu ver, não seriam necessariamente mais "vinculativas" do que os laços de família, de amizade, de gratidão, e lealdade que os une. Nesse grupo pequeno, se A faz alguma coisa para o benefício de $B$, movido unicamente pela exigência que recai sobre ele de respeitar a propriedade privada de $B$, ou de cumprir a promessa que fez a B, sem se sentir relativamente a $B$ vinculado por laços de amizade ou lealdade, então A poderia até mesmo ser moralmente criticado por B, e pelos demais membros do grupo. Um filho que, por exemplo, se abstém de se apossar de um objeto de sua mãe apenas por respeito à propriedade privada da mãe poderá estar sendo justo, mas a falta do afeto relevante aqui pode ser considerada moralmente pior do que a injustiça que haveria em se apossar do objeto em questão. Em um grupo pequeno, quando um indivíduo A não age em conformidade com as expectativas normativas dos outros membros do grupo, não é necessário dizer que A faltou com a palavra, ou roubou alguma coisa de um outro membro do grupo. É suficiente que A seja lembrado dos laços que o vinculam aos demais membros do grupo, ou que A seja lembrado da história compartilhada que possui com os demais membros do grupo. A instituição da justiça pode ser criada nesse grupo, mas ela não será mais "vinculatória" para seus membros do que os laços de amizade, laços de família, e vários tipos de relações afetivas com bases nos quais o grupo se organiza.

Mas surge agora uma questão importante: o que os membros de um grupo pequeno podem esperar dos indivíduos que não fazem parte de seu próprio grupo? Como eles devem agir relativamente aos indivíduos com os quais eles não têm nenhum laço de família, nenhum vínculo de amizade, 
nenhum sentimento de gratidão, nenhuma relação afetiva especial, e nenhuma história pessoal compartilhada? Para evitar a insegurança decorrente da interação com pessoas com as quais o grupo não tem nenhum vínculo afetivo, nenhum laço de amizade, nenhuma história compartilhada, o grupo poderia simplesmente se recusar a interagir com outros indivíduos. Mas essa é uma opção viável apenas enquanto os recursos materiais de que o grupo depende forem abundantes, e enquanto o encontro com outros indivíduos, estranhos ao grupo, for contornável.

Para evitar o contato com outras pessoas, estranhas ao grupo, uma estratégia aqui seria tentar promover uma gradual ampliação do grupo. Se os recursos naturais forem relativamente abundantes, os membros do grupo poderiam, por exemplo, tentar incrementar a taxa de natalidade. Afinal, se ter alguns amigos e parentes é bom, ter muitos amigos e parentes deveria ser ainda melhor. Um incremento no tamanho do grupo poderia, pelo menos à primeira vista, promover tanto a "segurança externa" quanto a "segurança interna" do grupo. A segurança externa seria promovida porque possíveis intrusos se sentiriam dissuadidos da tentativa de interferir na vida de um grupo relativamente grande e coeso. A segurança interna seria promovida através da ampliação da rede de laços de amizade, lealdade, gratidão, benevolência, etc. entre os seus membros. Por outro lado, no entanto, os indivíduos poderiam também antever (ou constatar retrospectivamente) o custo que essa estratégia envolveria a longo prazo: à medida que o grupo for crescendo haverá menos interação de um mesmo membro do grupo com todos os demais membros do grupo. Na situação original todos conhecem todos, todos mantêm vínculos com todos. Mas com o gradual crescimento do grupo todos conhecerão todos apenas pela mediação de terceiros ${ }^{5}$. Os laços de família, vínculos de amizade, sentimentos de gratidão, e histórias pessoais compartilhadas não terão mais a mesma "força normativa" que tinham originalmente. $\mathrm{E}$ o que é pior: o enfraquecimento dessa rede de "vínculos" recíprocos de um grupo em expansão traz consigo a ameaça das facções: os indivíduos poderiam gradualmente se sentir mais fortemente "vinculados" a subgrupos dentro do grupo do que ao grupo como um todo. A existência de facções, por sua vez, coloca em risco tanto a segurança interna quanto a segurança externa do grupo.

Qual seria então o tamanho ideal para que um grupo pudesse auferir os benefícios de sua ampliação, sem no entanto comprometer a coesão interna promovida por uma rede de laços de família, vínculos de amizade,

5 Hume chama atenção para esse tipo de problema em A Treatise of Human Nature (1978, p. $479 ; 487 ; 489 ; 492 ; 535)$. 
e sentimentos como lealdade, gratidão, e benevolência? Aparentemente, a resposta para essa questão é: 150 membros.

Hume, evidentemente, não discute a questão sobre quanto um grupo poderia continuar crescendo até que sua rede de "vínculos" recíprocos comece a enfraquecer. Mas Hume, por outro lado, procurou empregar no âmbito de sua investigação moral e política os mesmos procedimentos empíricos das ciências de sua época ${ }^{6}$. Por essa razão, não me parece que seria metodologicamente equivocado buscar na antropologia e na neurociência contemporâneas a resposta para um problema que decorre da interpretação de uma investigação filosófica iniciada por Hume. Na verdade, autores como, por exemplo, Michael Frazer, Simon Blackburn, e Knud Haakonssen chegam mesmo a se referir a Hume como uma espécie de "proto-darwinista"7. Frazer chama atenção para o débito intelectual de Darwin relativamente a Hume e sugere que "uma abordagem darwiniana acerca de nossa compreensão dos sentimentos morais poderia se mostrar extremamente útil tanto para filósofos quanto para cientistas"8.

\section{O número de Dunbar}

Uma "abordagem darwiniana" da filosofia moral de Hume, a meu ver, poderia partir de algumas pesquisas realizadas desde o final da década de 1980 por Robin Dunbar e sua equipe. Segundo Dunbar, nossa capacidade de nos inter-relacionamos pessoalmente com outras pessoas, e de compartilharmos com elas uma história pessoal, laços de família, e vínculos de lealdade, é limitada a um número máximo de aproximadamente 150 indivíduos. Esse número está correlacionado, segundo Dunbar, ao tamanho médio do neocórtex dos seres humanos. O tamanho médio do neocórtex de outros primatas determina também, da mesma forma, o número máximo de indivíduos que seus respectivos grupamentos sociais podem comportar.

Mamíferos como, por exemplo, elefantes e baleias possuem cérebros maiores do que o cérebro dos primatas. Mas quando se correlaciona a massa corporal à massa do cérebro, percebe-se que primatas têm um cérebro relativamente maior do que o cérebro da maior parte dos outros

6 Cf. Hume (1978, p. xvii-xix).

7 Blackburn (2008, p. 13): "He [Hume] was a Darwinian before his time, apostle, if anything, of evolved human nature and human sentiment." Cf. Haakonssen (2004, p. xxiii).

8 Frazer (2010, p. 185): “There is a strong proto-Darwinian strain throughout Enlightenment sentimentalism. Although it will not be a major theme of this book, this proto-Darwinism would be a fruitful focus of future research, both for purposes of informing contemporary moral philosophy and (given that Darwin himself was an avid reader of Hume) for purposes of an intellectual genealogy of Darwinism. A Darwinian approach to understanding the moral sentiments may prove extremely fruitful for philosophers and scientists alike." Cf. Ruse (1989). 
animais ${ }^{9}$. Uma teoria que se tornou bastante influente na literatura científica para explicar o tamanho relativamente grande do cérebro dos primatas é aquela que correlaciona o tamanho do neocórtex dos primatas à complexidade de seus respectivos grupamentos sociais. Essa teoria foi inicialmente denominada "hipótese da inteligência maquiavélica" (Machiavellian intelligence hypothesis), mas atualmente ela é mais comumente conhecida como "hipótese do cérebro social" (social brain hypothesis $)^{10}$.

A hipótese do cérebro social sugere que a capacidade que os primatas têm para viver em grupos sociais complexos está subordinada a uma competência cognitiva específica: a capacidade de não apenas reconhecer quem pertence e quem não pertence ao seu grupo, mas também de monitorar as relações que vão se estabelecendo e se modificando entre todos os demais membros do grupo ${ }^{11}$. Se o membro de um grupo tiver, por exemplo, um conflito com outro membro do grupo, é importante saber antecipadamente quem virá ao socorro de quem, pois isso determina quem terá mais chances de sair ganhando ou perdendo caso o conflito escale para um confronto físico direto. É preciso saber, com outras palavras, não apenas quem são meus amigos, mas também quem são os amigos dos meus amigos. O problema, porém, é que a teia de relações mútuas dentro de um determinado grupo cresce exponencialmente à medida que o grupo vai se tornando mais numeroso ${ }^{12}$. Em um grupo de 4 indivíduos cada um têm de conhecer sua própria relação com os 3 outros membros do grupo, assim como a relação que esses 3 mantêm entre si. Isso exige de cada indivíduo uma capacidade de monitorar 6 interelações ao mesmo tempo. Em um grupo de 5 indivíduos esse número sobe para 10 interelações; e em um grupo de 10 indivíduos o número de interelações cresce para 45. Ao atingir um número de 150 indivíduos cada membro precisa

9 Dunbar (1997, p. 56; 58); Dunbar (1992, 482).

10 Dunbar et al. (2007, p. 127): "The 'social brain hypothesis' refers to the fact that primates have unusually large brains compared to other animals and that these enhanced cognitive capacities are related to the fact that they have a more complex social life. At the core of this lie the concepts of trust and obligation, which enable individuals to co-operate in groups to solve the problems of survival and successful reproduction in more efficient ways." Cf. Dunbar (2010, p. 23); Dunbar (2001, p. 179); Dunbar (1998, p 178); Byrne e Corp (2004, p. 1693).

11 Dunbar et al. (2007, p. 113-114): "It is now widely recognized that primates' large brains are significantly associated with the distinctive social skills that primates display, an explanation known as the social brain hypothesis. The social brain hypothesis suggests that the demands of living in permanent social groups selected for a kind of intelligence that was particularly adept at tracking the relationships that exist between oneself and all the other members of the group and, more importantly perhaps, keeping track of the relationships that the other animals in the group have with each other. [...] The main evidence to support this hypothesis comes from a series of studies by Robin Dunbar and his co-workers, which showed that relative neocortex volume correlates with various measures of social complexity across the primates."

12 Dunbar (1997, p. 63-64). 
então processar informações referentes a 11.175 interelações diferentes. ${ }^{13}$ Segundo a "hipótese do cérebro social" é essa competência cognitiva que determina o número máximo de indivíduos que o grupamento de uma determinada espécie de primatas pode comportar. A região do cérebro dos primatas associada a essa competência cognitiva é o neocórtex. ${ }^{14}$

Ao estudar o comportamento social de diferentes espécies de primatas, Dunbar constatou que quanto maior o neocórtex maior é também o número de indivíduos que convivem no interior de um mesmo grupo. Com outras palavras: o número de indivíduos do grupamento social típico de uma determinada espécie de primatas é proporcional ao tamanho do neocórtex característico dessa espécie. Dunbar usou então a curva que descreve essa correlação para determinar qual seria então o número característico de indivíduos em grupamentos de seres humanos. ${ }^{15}$ O resultado a que ele chegou foi o seguinte: o tamanho de nosso neocórtex limita a um número de aproximadamente 150 indivíduos o tamanho de um grupamento social tipicamente humano. Esse resultado passou a ser conhecido como "número de Dunbar" (Dunbar's number).

O número de Dunbar poderia parecer pouco intuitivo à primeira vista. Afinal, somos capazes de participar ativamente da vida social de grupos que seguramente excedem um número de 150 indivíduos, tais como, por exemplo, condomínios, bairros, vilarejos, e cidades. No entanto, o que está em questão na hipótese de Dunbar é a pergunta sobre o número máximo de pessoas com as quais poderíamos nos inter-relacionar pessoalmente em uma dada época de nossas vidas. Sobre isso Dunbar afirma o seguinte:

A cifra de aproximadamente 150 parece corresponder ao número de pessoas cuja relação com você é explícita e pessoal, com uma história de interações passadas e algum nível de intimidade. Essas são as pessoas com as quais você procura manter contato, em cujas trajetórias de vida você tem um interesse maior do que meramente casual. São pessoas que, você sente, estariam dispostas a ajudá-lo com um favor - principalmente porque há entre vocês um senso de obrigação, seja por causa de algum

13 Imagine, por exemplo, que cada ponto no vértice de um pentágono represente um indivíduo em um grupo de 5 pessoas. As laterais e diagonais do pentágono representarão então a rede de interelações vigentes entre os 5 indivíduos do grupo. Segundo a "hipótese do cérebro social" cada indivíduo tem de monitorar todas as interações vigentes no grupo, ou seja: monitorar não apenas as relações que ele mantém com os demais, mas também as relações que os demais mantêm entre si. Para um grupo com $N$ indivíduos o número de interelações $R$ vigentes no grupo será: $R=\mathrm{N}[(\mathrm{N}-1) / 2]$

14 Dunbar (2010, p. 23): "Just as a computer's ability to handle complex tasks is limited by the size of its memory and processor, so the brain's ability to manipulate information about the constantly changing social domain may be limited by the size of its neocortex."

15 Dunbar et al. (2007, p. 115); Dunbar (1997, p. 63). 
nível de intimidade, seja por causa de uma obrigação de família ou de amizade, em uma organização ou comunidade ${ }^{16}$.

Uma pessoa A pode saber, com relação a um dado conjunto de indivíduos, por exemplo, quem é pai de que quem, quem é amigo de quem, quem é casado com quem, e quem é brigado com quem. Essas pessoas, por sua vez, também sabem qual é a posição que $A$ ocupa relativamente a elas nessa teia de interelações. Esse conhecimento mútuo decorre de uma história pessoal compartilhada, de vínculos afetivos, e de laços de lealdade que permitem às pessoas avaliar, por exemplo, quais são as outras pessoas relativamente às quais elas se sentem mais ou menos obrigadas a amparar em uma situação de dificuldade, ou a não deixar de cumprimentar ao encontrá-las por acaso na rua ou numa fila de banco. No entanto, não é difícil de perceber que deve haver um limite para o número de pessoas com as quais podemos ter laços ou vínculos recíprocos desse tipo. A hipótese de Dunbar é que esse limite corresponde a um número de aproximadamente 150 pessoas. Esse número está subordinado, não a uma falha de nosso caráter, mas ao tamanho do neocórtex de seres humanos. Esse limite, portanto, varia ao compararmos diferentes espécies de primatas, mas ele se mantém relativamente estável no interior de cada espécie ${ }^{17}$.

Dunbar chama atenção para algumas evidências que sugerem que o "número de Dunbar" se manteve relativamente estável para seres humanos desde pelo menos meados do período neolítico. Vilarejos do período neolítico (6000 a.C.) tinham cerca de 150 a 200 habitantes. Vilarejos ingleses do século XVIII tinham cerca de 160 habitantes. As comunidades cristãs huteritas, cujas origens remontam ao século XVI,

16 Dunbar et al. (2007, p. 120): "The figure of approximately 150 seems to correspond to the number of people whose relationship to you is explicit and personal, with a history of past interactions and some level of intimacy. These are the people with whom you like to try and maintain contact, in whose life histories you have more than a passing interest. They are the people who, you feel, would be willing to help you with a favour - mainly because there was a sense of obligation between you, either because of some level of intimacy or because of an obligation of kinship or fellowship in an organization or community." Cf. Dunbar (1997, p. 77): "[...] the human brain cannot sustain more than a certain number of relationships of a given strength at any one time. The figure of 150 seems to represent the maximum number of individuals with whom we can have a genuinely social relationship, the kind of relationship that goes with knowing who they are and how they relate to us." Dunbar (2010, p. 28); Dunbar (2001, p. 180-181).

17 Dunbar et al. (2007, p. 116): "Humans fit this primate relationship between group size and neocortex size surprisingly well. The typical size of huntergatherer communities (around 150 individuals) is exactly the size predicted by the relationship between group size and neocortex volume in primates (and, specifically, the relationship for apes). In traditional horticultural societies, villages typically consist of around 150 people. More importantly, recent studies suggest that this size of social grouping may even be characteristic of postindustrial societies." 
têm uma média de aproximadamente 110 membros. As comunidades huteritas se dividem quando atingem um número de aproximadamente 140 membros. A partir desse número os membros da comunidade consideram mais difícil preservar a estabilidade do grupo unicamente por meio de relações pessoais e "sanções informais" (peer pressure). ${ }^{18}$ Instituições militares modernas costumam ser divididas em pelotão, companhia, batalhão, regimento, divisão, etc. As "companhias", que são a unidade básica de combate, costumam ter um contingente que pode variar de 80 a 250 soldados. Dunbar sugere que esse número se manteve relativamente estável desde a época dos antigos romanos porque a confiança mútua necessária para garantir o sucesso das companhias em campos de batalha seria comprometida se o seu contingente excedesse muito o "número de Dunbar"19.

Se a hipótese de Dunbar é correta, então não é difícil de compreender qual é a sua implicação para a filosofia moral. Enquanto o tamanho de um grupo não ultrapassar o limite previsto pelo "número de Dunbar", conflitos de interesse no interior de um dado grupo podem ser facilmente administrados - ou talvez nem sequer surjam - através dos vínculos afetivos, dos laços de lealdade, e da história pessoal compartilhada entre os membros do grupo. Mas como não temos a capacidade cognitiva de monitorar um número que ultrapasse bastante o limite representado pelo número de Dunbar, teremos então de contar com um "esquema" artificial de restrições mútuas para podermos interagir com as pessoas com as quais não temos vínculos afetivos, laços de lealdade, ou uma história pessoal compartilhada. Esse "esquema", para Hume, é a convenção da justiça. Sem a convenção da justiça não podemos ter a expectativa de que possa haver uma cooperação social mais ampla, que se estenda para além dos limites de um círculo de amigos, parentes, e conhecidos.

A ampliação do âmbito da cooperação social não surge como uma simples opção. Ela é inevitável e indispensável. Algumas pessoas podem até preferir viver entre os huteritas, em kibutzim, ou em outras formas de comunidades alternativas. Mas de um modo ou de outro elas acabam tendo de contar com a cooperação de outras pessoas, externas à própria comunidade. Karl Peter relata, por exemplo, que algumas comunidades

18 Peter (1987, p. 61): "The number of Hutterites living in a single community is seldom less than sixty and equally seldom exceeds 140 . Under the existing division of labour and given the specific age structure of the population, sixty members seems to be the minimum to keep a community functioning while 140 members designates the functional upper limit. Beyond this point competition for positions becomes so intense that it threatens the unity of the community. The community usually branches out to alleviate such disruptive pressures." Cf. Dunbar (2010, p. 28).

19 Cf. Dunbar (2011); Dunbar (2010, p. 25-28); Dunbar et al. (2007, p. 123); Dunbar (1997, p. 71-75). 
huteritas têm de recorrer a empréstimos bancários para poder financiar a bipartição do grupo e subsequente fundação de uma nova colônia. ${ }^{20}$ Comunidades pequenas e fechadas como essas têm ainda de contar com a proteção do Estado em que estão situadas. Além disso, membros dessas comunidades, presumo, certamente não deixarão de confiar nos serviços de cirurgiões quando a vida de um de seus membros depender disso. Parece-me bem pouco provável que técnicas cirúrgicas complicadas pudessem ter surgido no passado, tendo sido gradualmente aperfeiçoadas e preservadas de uma geração para outra, se elas tivessem sido confinadas aos limites de uma comunidade fechada e pequena.

Talvez a principal desvantagem da vida no interior de comunidades fechadas e pequenas seja justamente estagnação do conhecimento e das técnicas que essas comunidades possam vir a criar autonomamente. Ainda que algumas pessoas possam descobrir, por exemplo, que tais e tais plantas são adequadas para o tratamento de tais e tais doenças, esse conhecimento pode facilmente se perder se ele não se disseminar para além dos limites de uma comunidade de poucos indivíduos. Do ponto de vista evolucional, essa capacidade de não apenas adquirirmos conhecimento e desenvolvermos técnicas para a transformação do mundo natural, mas de também preservarmos e transmitirmos esses conhecimentos e técnicas de uma geração para outra deve ter dependido de uma capacidade para interagirmos de modo produtivo com indivíduos que não fazem parte do nosso círculo imediato de amigos, parentes, e conhecidos. As regras de justiça criam então as condições para que essa interação mais ampla possa ocorrer.

\section{Implicações metodológicas}

Poderia talvez ser apresentada agora uma importante objeção contra o argumento que apresentei até aqui. A objeção é a seguinte: Hume não estava realmente interessado na pergunta sobre como a convenção da justiça surgiu. O mesmo poderia ser dito com relação a Locke, Kant e outros autores modernos e contemporâneos na tradição do contrato social que discutiram o conceito de justiça: a questão sobre a origem do Estado, ou sobre a origem da moralidade, não deveria ser confundida com a questão filosófica sobre as razões que temos para endossar as exigências que o Estado e a moralidade dirigem a nós. A ficção do "estado de natureza", portanto, não seria um problema para ser examinado com as ferramentas da antropologia, da teoria da evolução, ou da neurociência. Trata-se de um problema que concerne unicamente a filósofos.

20 Peter (1987, p. 146). 
No entanto, essa compreensão acerca da metodologia da filosofia moral me parece equivocada. Ao especularmos sobre as razões que os indivíduos teriam, em um hipotético "estado de natureza", para criar a convenção da justiça, ou para estabelecer os princípios de uma sociedade política, temos de assumir, de modo implícito ou explícito, a plausibilidade de uma determinada concepção de "natureza humana". Temos de contar, por exemplo, com uma compreensão acerca dos limites de nossas capacidades físicas e cognitivas. Temos de contar também com uma compreensão acerca das motivações e sentimentos que consideramos mais básicos em qualquer ser humano. Assumimos, por exemplo, que as pessoas não têm um anel de Gyges que as torna invisíveis às punições das lei, ou que elas não são capazes de descobrir por telepatia quais são as reais intenções de outras pessoas. Essas são suposições bastante razoáveis! Mas muitas teorias da justiça se comprometeram com teses bem mais substancias acerca das capacidades e motivações dos indivíduos em um hipotético estado de natureza. Alguns autores sugerem, por exemplo, que no "estado de natureza" já teríamos conhecimento de nossos "direitos naturais"; outros autores sugerem que seríamos movidos pelo constante medo da morte violenta; ou ainda que a "razão pura prática" (supondo que exista uma) nos permitiria determinar autonomamente a coisa a certa a se fazer; ou que na "posição original" já teríamos um senso de fairness. Mas a dificuldade aqui é sabermos se nossas intuições sobre as capacidades e motivações dos indivíduos em um hipotético "estado de natureza" não seriam já o resultado das capacidades e motivações que adquirimos pela influência mesma das instituições que buscamos justificar. Rousseau parece ter sido o primeiro autor a chamar atenção para esse problema metodológico: "Já observei, e não posso repetir em demasia, que o erro de Hobbes e dos filósofos consiste em confundir o homem natural com o homem situado diante de seus olhos, transpondo em um sistema o ser que só pode existir em outro". ${ }^{21}$ Disso não se segue, porém, que Rousseau seja imune ao problema para o qual chama atenção. Rousseau se comprometeu com uma concepção bastante romântica - e por isso mesmo problemática - de natureza humana, uma concepção que havia se tornado bastante atrativa em sua própria época. Se não quisermos nos comprometer com uma concepção romântica de natureza humana, uma alternativa seria então partirmos de uma concepção que seja no mínimo compatível com o que sabemos de nossa história evolutiva, e que seja além disso tão coerente quanto possível com as ciências empíricas de nossa época. Mas isso, por outro lado, não significa "reduzir" a filosofia moral a especulações

$\overline{21}$ Rousseau (2003, p. 58). 
cientificistas. Bernard Williams certamente tinha razão para desprezar esse tipo de reducionismo quando afirmou ou seguinte em uma entrevista:

As pessoas que eu realmente desprezo são os teóricos da evolução reducionistas, do tipo moralmente pouco imaginativos, que em nome da ciência pensam que eles podem explicar tudo em termos dos nossos ancestrais hominídeos, ou em termos de nossos genes, com um misto de arrogância e desconsideração pela história. Uma tal especulação reducionista encoraja um cientificismo realmente vazio ${ }^{22}$.

Ao chamar atenção aqui para o "número de Dunbar" minha intenção não foi a de reduzir nossa compreensão acerca da moralidade a uma explicação sobre o modo de vida dos "primeiros hominídeos", nossos "ancestrais". Minha intenção foi basicamente mostrar que mesmo nossos ancestrais optariam por criar a convenção da justiça, não tanto para evitar uma "guerra de todos contra todos", ou para garantir a proteção de seus "direitos naturais", mas para superar algumas desvantagens que há em viver em comunidades que não ultrapassem, em número de membros, o limite previsto pela hipótese de Dunbar ${ }^{23}$.

\section{Referências}

BLACKBURN, S. Hume. Londres: Granta, 2008.

BYRNE, W.; CORP, N. "Neocortex size predicts deception rate in primates". Proceedings of the Royal Society: Biological Sciences, 271 (2004), p. 1693-1699.

DUNBAR, Robin. "Friends to count on: The perfect number for a human social group is 150. The challenge is maintaining a real sense of community". In: The Guardian, Londres, (25 de abril 2011). Disponível em: <http://gu.com/p/2zj9b/sbl>.

. "Dunbar's number". In: How many friends does one person need? Dunbar's number and other evolutionary quirks. Cambridge (Mass.): Harvard University Press, 2010, p. 21-34.

. "Brains on two legs: Group size and the evolution of intelligence". In: WALLL, Frans B. M. (Ed.). Tree of origin: What primate behaviour can tell us about human social evolution. Cambridge (Mass.): Harvard University Press, 2001, p. 173-191.

p. 178-190.

. "The social brain hypothesis". Evolutionary Anthropology, 6(5) (1998),

\footnotetext{
22 Williams (2002): "The people I really do dislike are the morally unimaginative kind of evolutionary reductionists who in the name of science think they can explain everything in terms of our early hominid ancestors or our genes, with their combination of high-handed tone and disregard for history. Such reductive speculation encourages a really empty scientism.".

${ }^{23}$ Gostaria de agradecer Fábio Shecaira pela cuidadosa leitura e pelos comentários à primeira versão deste artigo.
} 
DUNBAR, Robin. "Of brains and groups and evolution". In: Grooming, gossip, and the evolution of language. Londres: Faber and Faber, 1997, p. 55-79.

. "Neocortex size as a constraint on group size in primates". Journal of Human



DUNBAR, Robin; BARRETT, Louise; LYCETT, John. "The social whirl”. In: Evolutionary psychology. A beginner's guide: Human behaviour, evolution and the mind. Oxford: Oneworld, 2007, p. 110-127.

FRAZER, M. The enlightenment of sympathy: Justice and the moral sentiments in the eighteenth century and today. Oxford: Oxford University Press, 2010.

HAAKONSSEN, Knud. "Introduction". In: Adam Smith: A theory of moral sentiments. Cambridge: Cambridge University Press, 2004.

HUME, David. (1751). "An enquiry concerning the principles of morals". In: Hume's Moral and Political Philosophy, ed. Henry Aiken. New York: Hafner, 1968, p. 173-294. . (1739/1739). A treatise of human nature, ed. L. A. Selby-Bigge. Oxford: At the

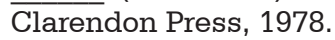

. "On the original contract". In: David Hume: Political essays. (Cambridge texts in the history of political thought), ed. K. Haakonssen, 1994, p. 186-201.

PETER, K. The dynamics of hutterite society: An analytical approach. Alberta: The University of Alberta Press, 1987.

ROUSSEAU, J. J. "O estado de guerra nascido do estado social". In: Rousseau e as relações internacionais. Tradução Sérgio Bath. São Paulo: Imprensa Oficial, 2003, p. 47-59.

RUSE, M. "Darwin's debt to philosophy". In: The Darwinian Paradigm: Essays on its history, philosophy, and religious implications. Londres: Routledge, 1989, p. 9-34.

WILLIAMS, Bernard. "Bernard Williams: Carrying the torch for truth: Philosopher calculates the moral cost of rejecting the concept". In: SFGATE, São Francisco (USA), (22 set. 2002). Disponível em: < http://www.sfgate.com/books/article/Q-A-BernardWilliams-Carrying-the-torch-for-2767949.php>.

\section{Endereço postal:}

Instituto de Filosofia e Ciências Sociais/UFRJ

Av. Pedro Calmon, 550

Rio de Janeiro, RJ, Brasil

Data de recebimento: 22/08/2015

Data de aceite: 02/03/2016 